\title{
Solar Disinfection Water Treatment for a Community-Scale System: An Analysis of Design Parameters for Humanitarian Engineering Projects
}

\author{
Marni R. Kendricks \\ Assistant Dean, School of Engineering \\ The University of Mississippi \\ University, MS 38677-1848 \\ mckendri@olemiss.edu \\ Joanna L. David \\ Undergraduate, Department of Chemical Engineering \\ The University of Mississippi \\ University, MS 38677-1848 \\ Joanna.david11@gmail.com
}

\author{
Tracey E. Sisco \\ Undergraduate, Department of Civil Engineering \\ The University of Mississippi \\ University, MS 38677-1848 \\ Traceysisco1@gmail.com \\ Cristiane Q. Surbeck, P.E., Ph.D. \\ Assistant Professor, Department of Civil Engineering \\ The University of Mississippi \\ University, MS 38677-1848 \\ csurbeck@olemiss.edu
}

\begin{abstract}
SODIS, solar disinfection of water in plastic bottles, is a well-known water treatment method utilized in communities lacking water treatment infrastructure. While SODIS is commonly employed by individuals and family units needing clean drinking water, a larger, community-scale solar disinfection system is presented in this paper as an alternative, appropriate, humanitarian engineering technology. A community-scale system may be acceptable for communities that reject the individual-bottle SODIS method. To test the treatment effectiveness of such a system, experiments were conducted to quantify the solar inactivation rate of total coliform bacteria from contaminated source water. Solar disinfection configurations in tanks and bottles were analyzed for the effect of ultraviolet (UV) light index, water temperature, tank color, plastic covering, and duration of sun exposure. A black tank, covered with a clear, plastic drop cloth with a thickness of 2 MIL $(0.0508 \mathrm{~mm})$ provided an effective inactivation rate of total coliforms. A contour plot of UV index versus water temperature provides guidelines for minimum required sun exposure times for disinfection.
\end{abstract}

Index Terms - humanitarian engineering, solar disinfection, water treatment, total coliform bacteria, SODIS, batch treatment

\section{INTRODUCTION}

Safe drinking water is not available to 780 million people in the world. ${ }^{\mathrm{i}}$ This affected population lives in some of the poorest countries in the world, where resources for treating water are limited. Therefore, low-cost and easy-to-operate technologies are necessary to address the lack of clean drinking water to these populations. The World Health Organization (WHO) has recognized the effectiveness of solar water disinfection (SODIS) in 2-liter polyethylene terephthalate (PET) bottles for individual consumption and recommends its use. ${ }^{\text {ii }}$ Research literature indicates that SODIS can be effective and economical ${ }^{\text {iii iv }}{ }^{\text {in }}$ utilizing the sun's thermal and optical mechanisms as a means of inactivating microorganisms in water. ${ }^{v}$ Based on the effectiveness of the individual-bottle SODIS method on water disinfection and general community acceptance, this paper assessed a community-scale water treatment system utilizing such a system of solar 
disinfection. This could be considered an appropriate technology for solar disinfection in small communities that favor a centralized system.

This electricity-free and chemical-free treatment system for a community of 100-300 individuals could be established through humanitarian outreach efforts. The first stage would consist of an appropriate manual mechanism to pass water through a sand filter to remove suspended solids, improve taste, decrease turbidity, and remove microorganisms that are filtered by or adsorbed to the sand. This filtration can be accomplished by using one of the already developed and widely available sand filtration methods. Next would come the treatment that is the scope of the research reported in this paper. The filtered water would travel by gravity to a tank that would expose water to ultraviolet (UV) light from the sun to inactivate the microbiological contaminants (Figure 1). Laboratory-scale experiments of this potential system were conducted to determine the following parameters: (1) a viable protective covering over the sun exposure tank to prevent the introduction of contaminants caused by animals, windblown particles, rainfall, and other external sources; (2) the time required to disinfect water based on both the UV index and temperature, and (3) dimensions and color of the sun exposure tank. Ultimately, a chart is developed to help educate an operator on the effective amount of sun exposure time to produce disinfected potable water.

The objective of this study was to present insights into design options of an electricity- and chemical-free water treatment system consisting of a simple two-stage treatment process followed by bottling. The authors prepared this paper with the anticipation that humanitarian engineering organizations will consider this as an alternative appropriate technology to serve small communities in need of treated water. This technology is low-cost, low-maintenance, and uses natural processes. It can be implemented as micro-businesses to sell drinking water for a nominal price that would cover materials and labor to operate the system.

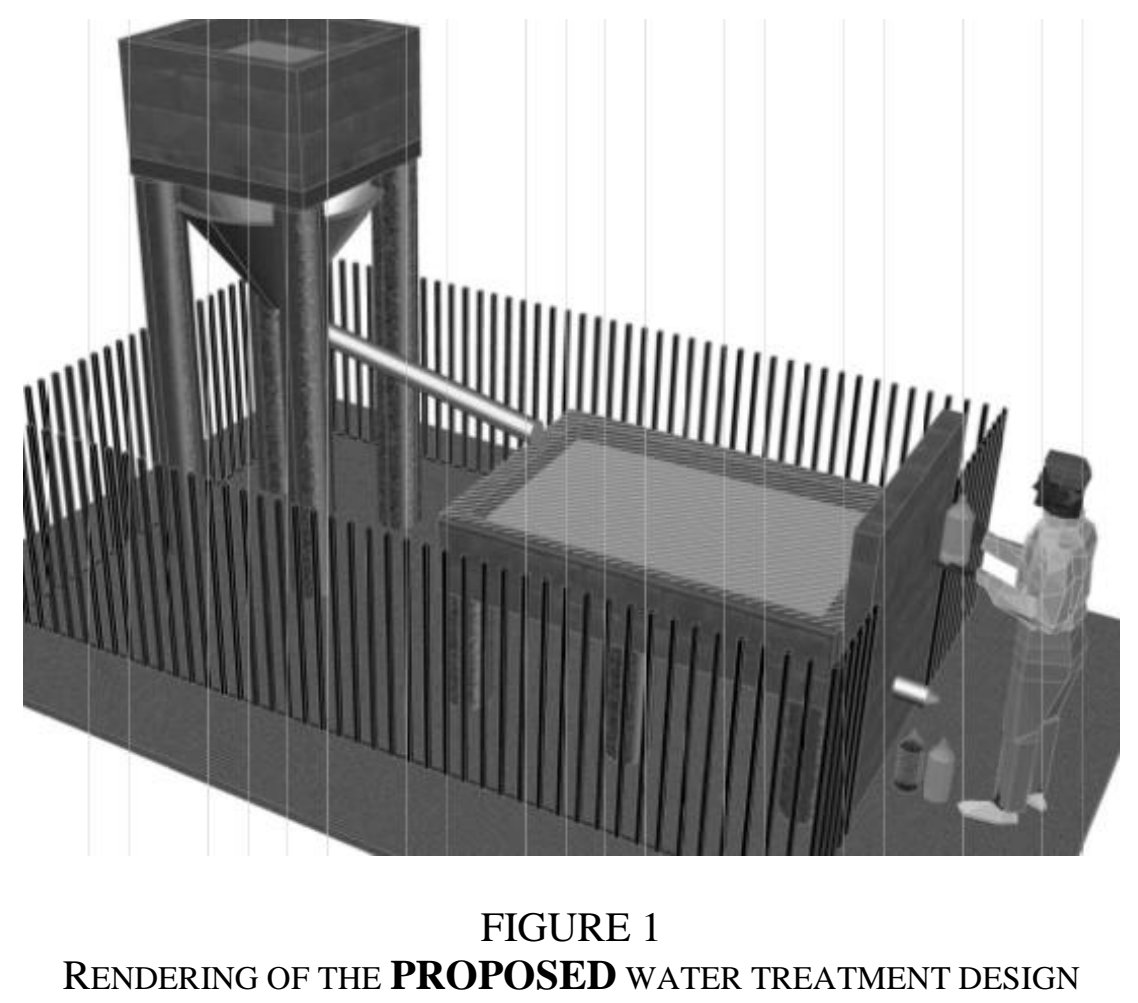


The elevated tank on the left contains sand for filtration and a plastic covering. The water moves by gravity from this tank, through the pipe, and into the plastic-covered sun exposure tank on the bottom right. A user collects water from the spigot on the right into a disinfected container.

\section{BACKGROUND}

Previous studies have shown that thermal properties of sunlight are useful for inactivating coliform and other bacteria, particularly above $50^{\circ} \mathrm{C}^{\mathrm{vi}}$, vii. The UV radiation from the sun provides an optical mechanism that breaks the molecular bonds in a microorganism's deoxyribonucleic acid (DNA) or ribonucleic acid (RNA), rendering it incapable of reproduction or of infecting a host ${ }^{\text {viii }}$.

UV light is the light with wavelengths between 100 and $400 \mathrm{~nm}$, and is subcategorized into UV-A (400-315 nm), UV-B (315-280 nm), and UV-C (280-100 nm), with the most successful inactivation occurring in the UV-C range ${ }^{\text {ix }}$. However, only waves in the UV-A and UV-B spectra reach the Earth's surface, though the combination of high temperatures of $50-60^{\circ} \mathrm{C}$, and UV-A or UV-B light, can inactivate most microbiological contaminants ${ }^{\mathrm{x}}$.

To use a simple measure of solar power available at any geographic location for this application, this study incorporated the use of UV index on a scale of zero to 15 (with zero being the lowest radiation), which is calculated by the U.S. National Weather Service (NWS) with a computer model using parameters of latitude, time of year, ozone, cloud cover, and elevation. The daily predicted UV Index is publically available and published for each defined area of the U.S. by geographic zip code or city on the U.S. Environmental Protection Agency SunWise website $^{\mathrm{xi}}$. This source of data for the geographic region of this study (Oxford, Mississippi, USA) was used consistently throughout the experiments. It is estimated that this study location would provide more conservative disinfection in terms of UV exposure than many developing countries along the equator and in tropical regions.

A covering for the sun exposure tank is necessary to protect the water from outside contaminants while providing the necessary transmittance of UV radiation and entrapment of heat. Because glass is not a viable covering option due to the possibility of breakage, a plastic covering is considered instead. In addition to transmitting UV light, the covering should also exhibit weather durability, resist significant discoloration, be readily available, and be economically feasible. However, many plastics are designed to inhibit UV transmission. Opaque plastics will block nearly all UV light, while other plastics may absorb or scatter light ${ }^{\mathrm{xii}}$. Therefore, experiments were performed to evaluate an appropriate covering for the tank.

\section{METHODS}

\section{Spectrophotometer Testing of Plastics}

To determine which plastics were viable options for a water disinfection tank covering, a spectrophotometer (UV-1201S, Shimadzu Scientific Instruments, Columbia, MD, USA) was used to measure the transmittance of UV light at the UV-A and UV-B ranges through six different plastic media, including: PET, OPTIX Acrylic Sheeting (2.4 mm thickness, Plaskolite, Inc., Columbus, OH, USA), LEXAN-Polycarbonate Sheeting (2.4 mm, SABIC, Pittsfield, MA, USA), and three Husky® Brand plastic drop cloths (Husky, Bolton, ON, Canada) with 
thicknesses of $0.018 \mathrm{~mm}(0.7 \mathrm{MIL}), 0.051 \mathrm{~mm}$ (2 MIL), and $0.102 \mathrm{~mm}$ (4 MIL) respectively. Samples of each plastic were tested against a standard blank quartz glass cuvette to determine transmittance percentages of light waves in the UV spectrum ranging from $250 \mathrm{~nm}$ to $400 \mathrm{~nm}$, in 10-nm intervals. Special consideration was given to the plastic drop cloths because of easiest delivery to remote communities. PET plastic, widely used material in SODIS treatment, was cut from a bottle and analyzed with the spectrophotometer for comparison with the other plastics.

\section{Solar Exposure Experiments}

The proper amount of time needed to provide adequate disinfection and the effect of the plastic covering were both determined from solar exposure experiments. Sample water simulating a possible unfit drinking water source was collected from a local lake in Oxford, Mississippi, USA. For each of the seven experiment dates, bacterial analysis was performed immediately after sample collection. All tests for total coliform and E. coli used the Colilert® Method (IDEXX Corporation, Westbrook, ME, USA) to yield concentrations in most probable number (MPN) per $100 \mathrm{~mL}$. Colilert ${ }^{\circledR}$ is also known as Standard Method $9223^{\text {xiii }}$. The temperature of the air was recorded using a probe thermometer (Fisher Scientific, Pittsburgh, PA), and the water temperature was recorded using an infrared thermometer (Fisher Scientific, Pittsburgh, PA, USA) rather than a probe thermometer in order to prevent cross contamination.

In the laboratory, the collected water was filtered through playground sand (\#1113, Quickrete, Atlanta, GA, USA) to remove some bacteria and suspended solids that could act as a shield between bacteria and UV light. After filtration, buckets were used to transport the water to a location where the water would receive direct, unobstructed sunlight. The water was then poured into shallow pans. Black pans and white pans, covered and uncovered, were used to determine if the black color would create an increase in water temperature compared to the white pan, and thus, an increase in the rate of disinfection (Figure 2). When plastic coverings were utilized in the experiment, the chosen material was a Husky® 2 MIL plastic drop cloth. A PET bottle, because its use is already well established in SODIS, was used as a comparison. 


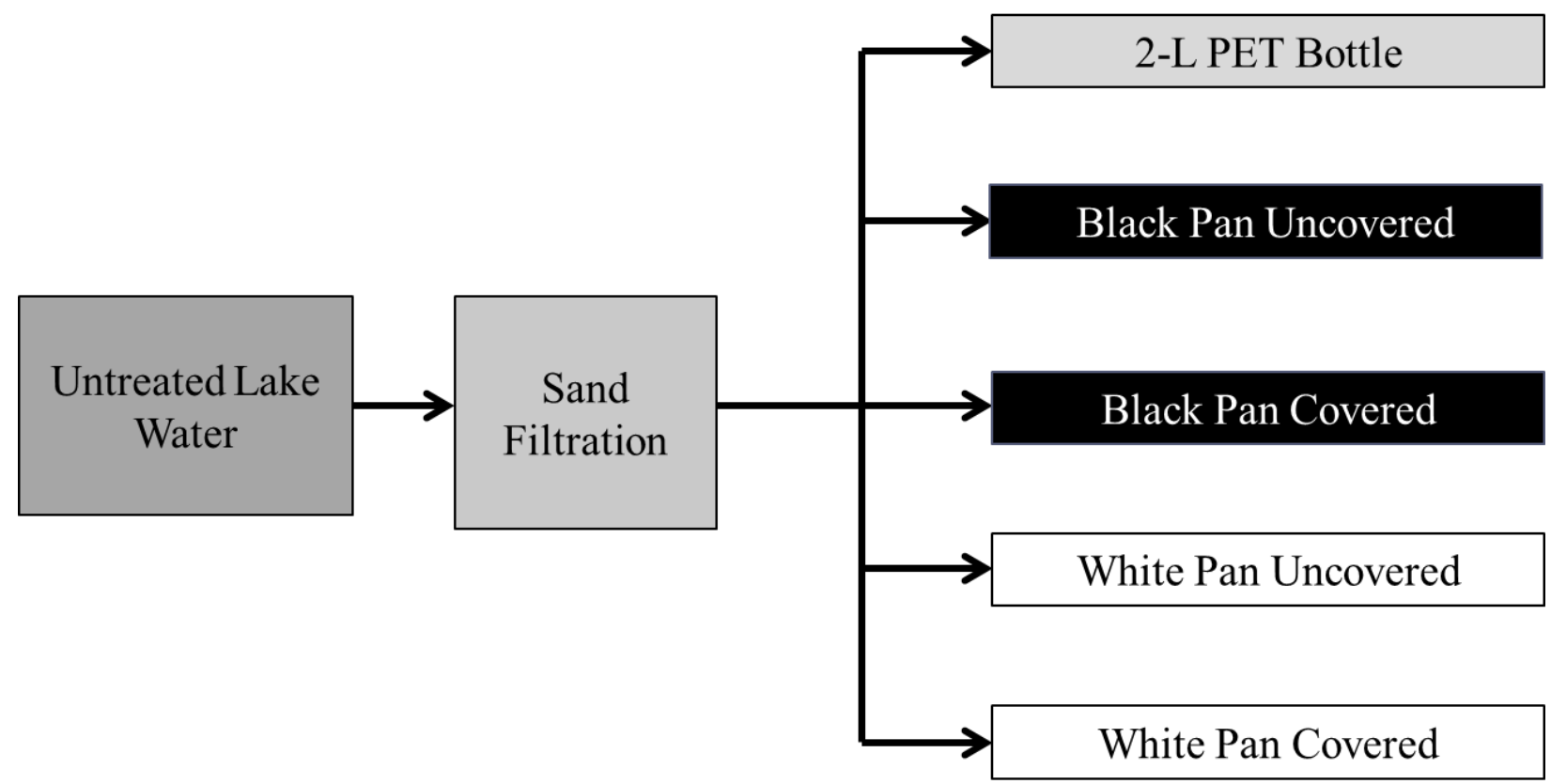

FIGURE 2

PROCESS FOR THE SOLAR EXPOSURE EXPERIMENTS

The water was then exposed to sunlight for four to six hours, generally starting at 10:00 AM. A sample was collected from each container (pan or bottle) every thirty minutes. Air and water temperatures were recorded at each sampling.

For all pans and bottles in each experiment, a graph of total coliform concentrations versus time was created. On each graph, an exponential decay best-fit curve was plotted. The equation of the curve is in the form of a first order decay reaction in a batch reactor:

$$
C_{t}=C_{o} \mathrm{e}^{-k t}
$$

where $C_{t}$ is the coliform concentration at a given time (dependent variable), $C_{o}$ is the coliform concentration before sun exposure (experimentally-determined constant), $k$ is the inactivation rate constant (numerically-determined constant from the curve fit), and $t$ is the exposure time (independent variable).

After the calculation of the inactivation constants, a multiple linear regression (MLR) was conducted using the software SPSS Statistics Version 21 (IBM Corporation, Armonk, NY, USA) with inactivation rate constant as the dependent variable and UV index and temperature as independent variables.

To test the effect of water depth on inactivation rate constants, sand-filtered water from the same lake water source was added to two identical containers at depths of 2.2 and $13.3 \mathrm{~cm}$. This experiment with depth of water was to determine a reasonable design parameter for the wall height of the sun exposure tank. If coliform bacteria were found to become inactivated at a depth of $13.3 \mathrm{~cm}$ as effectively as $2.2 \mathrm{~cm}$, then the length and width of the tank size could be designed accordingly. As an example, a sun exposure tank of $2000 \mathrm{~L}$ capacity would either be designed for a shallow 2.2-cm depth with a large base sun exposure area, or a 13.3-cm depth with a smaller base sun exposure area. 
To determine whether the coliform inactivation rates were indeed a result of exposure to UV and heat, and not just the natural inactivation rate, a control experiment was conducted in the dark at room temperature.

\section{RESULTS}

\section{Plastic Covering for a Sun Exposure Tank}

From a comparison of the spectrophotometer results, the Husky® drop cloth with a thickness of 2 MIL had the highest UV transmittance percentage at nearly every wavelength measured through the ranges of UV-A and UV-B. The 2-MIL drop cloth also allowed a greater transmittance of the UV-B spectra than the PET plastic, indicating higher energy levels and higher rates of disinfection ${ }^{\text {xiv }}$ through the 2-MIL drop cloth. The PET sample revealed nearly zero transmittance percentages in the UV-B and UV-C spectra, or at wavelengths below $320 \mathrm{~nm}$, but PET was shown to transmit UV-A. All other plastic samples tested revealed less UV transmittance. Table I shows a comparison of UV light transmitted through PET plastic and the plastic drop cloths (0.7-MIL, 2-MIL, and 4-MIL).

\section{TABLE I}

PERCENT TRANSMITTANCE OF UV LIGHT THROUGH 0.7-MIL, 2-MIL, AND 4-MIL DROP CLOTHS AND THROUGH PET

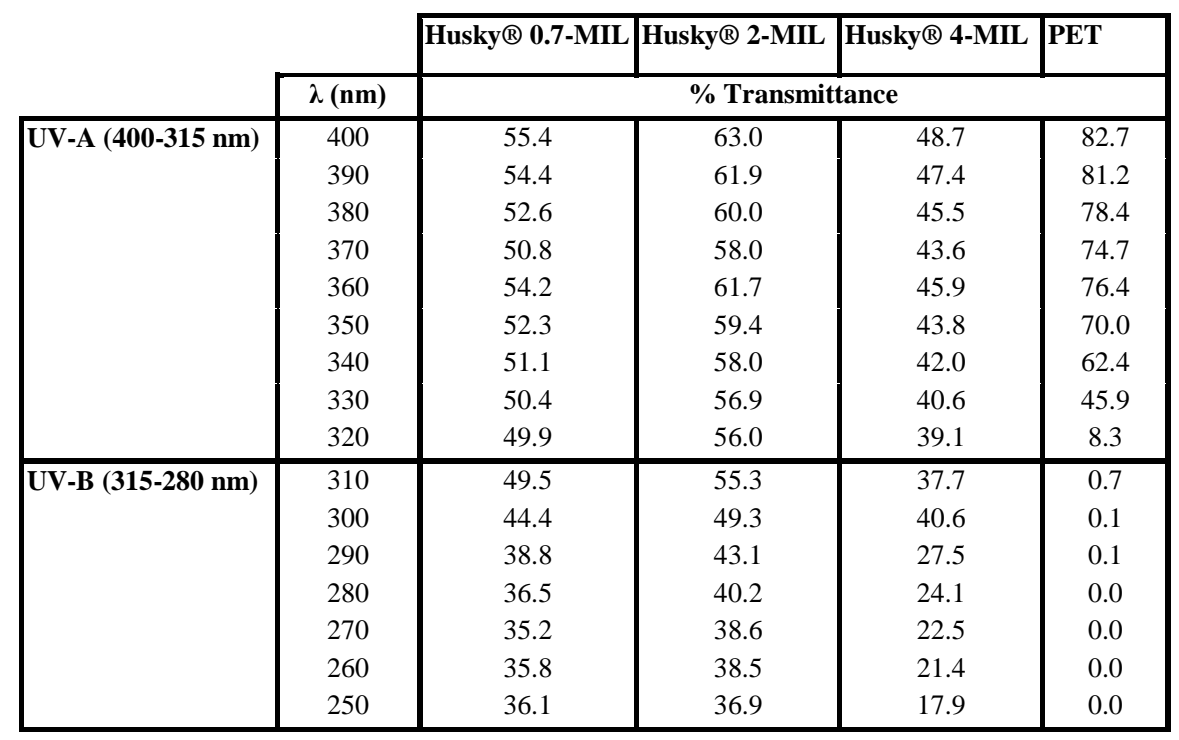

\section{Sun Exposure Testing}

Sixty to $80 \%$ of the total coliform bacteria concentrations were reduced by the sand filtration before any sunlight exposure (Table II). E. coli was not detected in significant concentrations in any of the experiments. Coliform concentrations decreased with four hours of sun exposure in each experiment (Table II), even when the temperature and UV were both low. A typical graph demonstrating the decrease in coliform concentrations during sun exposure is shown in Figure 3 , along with the first-order decay equation and the resulting $\mathrm{R}^{2}$ value for the curve. During the 
experiments, the mean water temperatures ranged from $17^{\circ} \mathrm{C}$ to $55^{\circ} \mathrm{C}$, and the UV indices ranged from 1 to 11 (see Table III). The highest inactivation rate constants $(k)$ corresponded with the combination of high temperature and high UV. Comparing the white and black pans, it can be observed from Table III that the black covered pans yielded higher water temperatures than the white covered pans. The weather varied for the seven experiments from sunny to completely overcast and rainy.

TABLE II

SUMMARY OF COLIFORM DATA

\begin{tabular}{|c|c|c|c|c|}
\hline \multirow{2}{*}{ Date } & Container Type & \multicolumn{3}{|c|}{ Coliform concentration (MPN/100mL) } \\
\cline { 2 - 5 } & & Raw Lake Water & $\begin{array}{c}\text { Filtered Lake } \\
\text { Water }\end{array}$ & $\begin{array}{c}\text { Water after 4 } \\
\text { hours of sun } \\
\text { exposure }\end{array}$ \\
\hline 9 Oct 2010 & 100-mL Polystyrene Bottles & NA & 3654 & $<10$ \\
\hline 16 Oct 2010 & P-B-U & NA & 2400 & 146 \\
\hline 23 Oct 2010 & P-B-U & NA & 275 & $<1$ \\
\hline 4 Mar 2011 & P-B-U & NA & 160 & 72.3 \\
\hline 4 Mar 2011 & 2-L PET Bottle & NA & 160 & 98.8 \\
\hline 8 Apr 2011 & P-B-U & 457 & 169 & 76.7 \\
\hline 8 Apr 2011 & 2-L PET Bottle & 457 & 146 & 24.6 \\
\hline 6 May 2011 & P-B-U & 3282 & 613 & 5.2 \\
\hline 6 May 2011 & P-B-C & 3282 & 686 & $<1$ \\
\hline 6 May 2011 & P-W-U & 3282 & 759 & 1 \\
\hline 6 May 2011 & P-W-C & 3282 & 686 & $<1$ \\
\hline 6 May 2011 & 2-L PET Bottle & 3282 & 686 & $<1$ \\
\hline 19 Aug 2011 & P-B-U & 8402 & 3231 & $<1$ \\
\hline 19 Aug 2011 & P-B-C & 8402 & 4106 & $<1$ \\
\hline 19 Aug 2011 & P-W-C & 8402 & 2382 & $<1$ \\
\hline
\end{tabular}

Abbreviations: NA = not available. P: Pan, B: Black, W: White, U: Uncovered, C: Covered with 2 MIL plastic drop cloth 


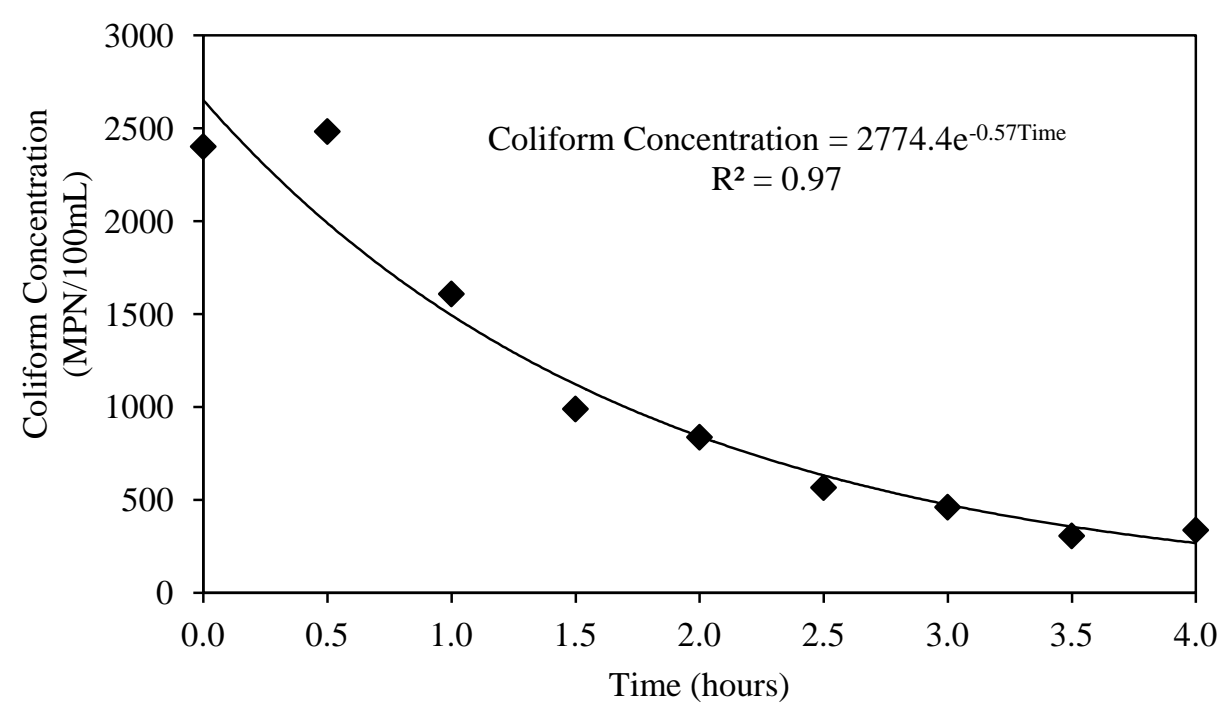

FIGURE 3

AN EXAMPLE, FROM THE EXPERIMENT CONDUCTED ON OCTOBER 16, 2010, OF TYPICAL INACTIVATION DATA SHOWING A FIRST-ORDER DECAY MODEL.

TABLE III

SUMMARY OF INACTIVATION DATA ANALYSIS

\begin{tabular}{|c|c|c|c|c|c|c|}
\hline Date & Container Type & $\begin{array}{c}\text { Mean Water } \\
\text { Temperature } \\
\text { (standard } \\
\text { deviation) } \\
\left({ }^{\circ} \mathrm{C}\right)\end{array}$ & UV Index & $\begin{array}{c}k \\
\left(\text { hour }^{-1}\right) \\
\end{array}$ & $\mathrm{R}^{2}$ & $\begin{array}{c}\% \text { Inactivation in } \\
4 \text { hours }\end{array}$ \\
\hline 9 Oct 2010 & $\begin{array}{c}\text { 100-mL Polystyrene } \\
\text { Bottles }\end{array}$ & $36(5.9)$ & 6 & 1.67 & 0.96 & 99.7 \\
\hline 16 Oct 2010 & P-B-U & $29(3.7)$ & 3 & 0.57 & 0.97 & 86.0 \\
\hline 23 Oct 2010 & P-B-U & $26(1.2)$ & 5 & 1.51 & 0.91 & 99.6 \\
\hline 4 Mar 2011 & P-B-U & $17(2.0)$ & 1 & 0.35 & 0.08 & 54.8 \\
\hline 4 Mar 2011 & 2-L PET Bottle & $18(2.0)$ & 1 & 0.25 & 0.04 & 38.3 \\
\hline 8 April 2011 & P-B-U & $24(4.0)$ & 4 & 0.14 & 0.36 & 54.6 \\
\hline 8 April 2011 & 2-L PET Bottle & $26(4.4)$ & 4 & 0.39 & 0.79 & 83.2 \\
\hline 6 May 2011 & P-B-U & $30(2.5)$ & 10 & 1.05 & 0.85 & 99.2 \\
\hline 6 May 2011 & P-B-C & $44(7.8)$ & 10 & 1.97 & 0.93 & 99.8 \\
\hline 6 May 2011 & P-W-U & $27(2.6)$ & 10 & 1.72 & 0.94 & 99.8 \\
\hline 6 May 2011 & $\mathrm{P}-\mathrm{W}-\mathrm{C}$ & $37(5.2)$ & 10 & 1.71 & 0.90 & 99.8 \\
\hline 6 May 2011 & 2-L PET Bottle & $31(3.7)$ & 10 & 0.93 & 0.93 & 99.8 \\
\hline 19 Aug 2011 & P-B-U & $36(4.6)$ & 11 & 2.12 & 0.90 & $>99.9 \%$ \\
\hline 19 Aug 2011 & P-B-C & $53(12.8)$ & 11 & 2.42 & 0.87 & $>99.9 \%$ \\
\hline 19 Aug 2011 & P-W-C & $44(8.1)$ & 11 & 2.50 & 0.93 & $>99.9 \%$ \\
\hline
\end{tabular}

Abbreviations: P: Pan, B: Black, W: White, U: Uncovered, C: Covered with 2 MIL plastic drop cloth

Once the inactivation rate constant was determined, the mean water temperature during sun exposure was plotted against the UV index, and contour lines of equal inactivation rate constants 
were created (Figure 4). Several data points, noted by gray shading in Table III, were not included in this graph for the following reasons. The experiment date with the low UV index of 1, 4 March 2011, was excluded because the exponential decay curve to determine the inactivation coefficient $k$ resulted in low $\mathrm{R}^{2}$ values (0.08 and 0.04). The experiment of 8 April 2011 with the uncovered container appeared to have received external contamination, and the $k$ curve resulted in a low $\mathrm{R}^{2}$ value of 0.36 . The experiments of 23 October 2010 and 6 May 2011 with the uncovered containers, although with high $\mathrm{R}^{2}$ values, also received external contamination (from field observations of debris appearing on the water) and were excluded from the contour plot of Figure 4.

The contour plots with and without these excluded points were compared and found to have similarities. The inactivation constant contours (Figure 4) are the same near $0.6 \mathrm{~h}^{-1}$ and $2.0 \mathrm{~h}^{-1}$. In between those numbers, the contours are more evenly distributed with the excluded points mentioned above, whereas the contours with all of the points are clustered around $26^{\circ} \mathrm{C}$ and a UV index of 4.

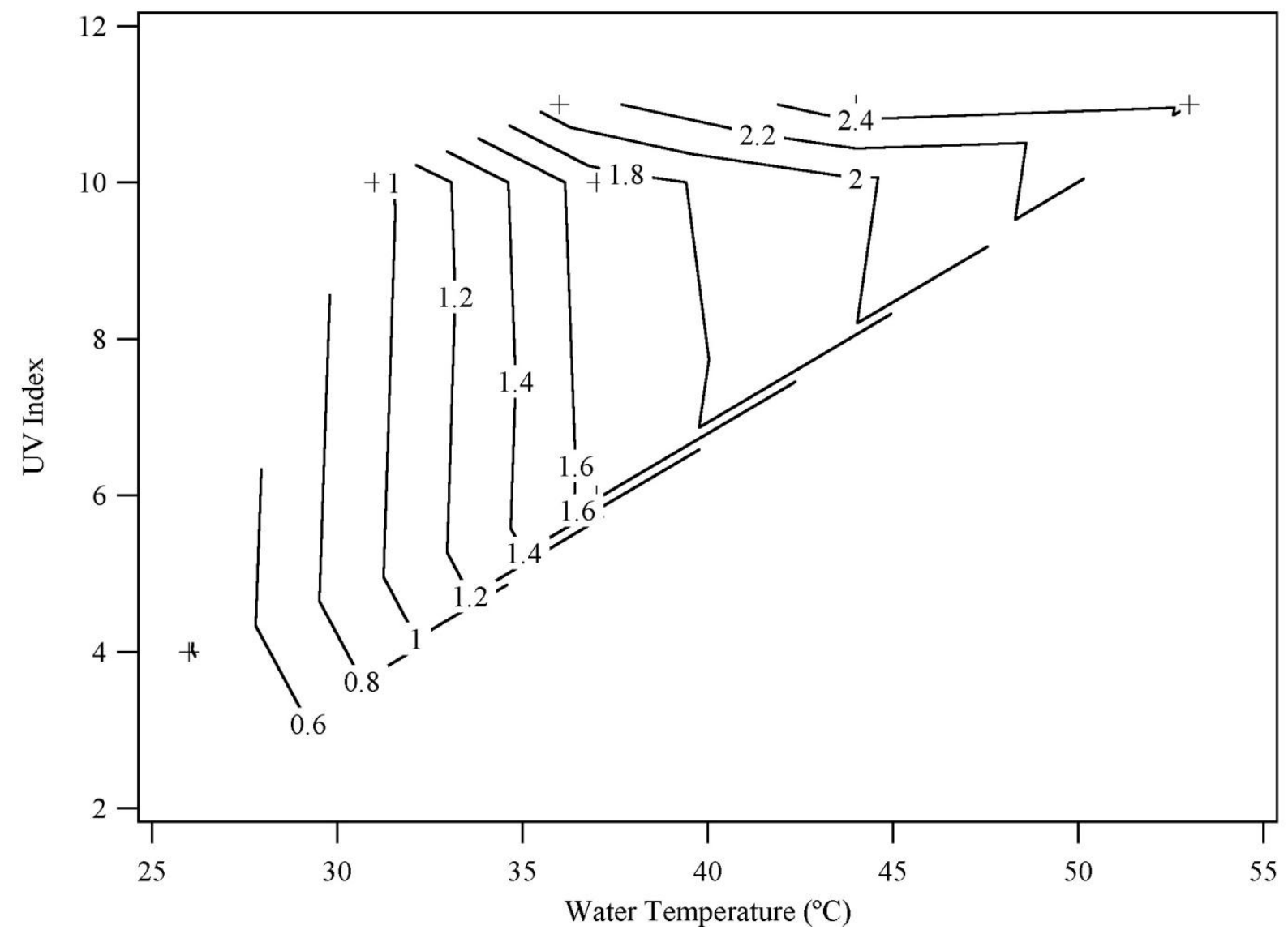

FIGURE 4.

CONTOUR PLOT OF INACTIVATION RATE CONSTANTS IN $\mathrm{H}^{-1}$. THE INACTIVATION RATE CONSTANT CAN BE FOUND FROM THE INTERSECTION OF THE VERTICAL LINE FROM THE WATER TEMPERATURE AXIS AND THE HORIZONTAL LINE FROM THE UV INDEX AXIS. 
The MLR analysis resulted in the following equation for predicting the inactivation rate constant:

$$
k=-1.362+0.091(U V \text { index })+0.058(\text { Temperature }) \text {, }
$$

where $k$ is the inactivation rate constant in units of $\mathrm{h}^{-1}, U V$ index is the number determined for a particular day on the previously given website, and Temperature is the average temperature of the water in degrees Celsius during the solar disinfection period. The model had an $\mathrm{R}^{2}$ of 0.821 $(\mathrm{p}=0.008)$. The Pearson correlation coefficient between UV index and water temperature was relatively low $(0.691, \mathrm{p}=0.020)$, meaning that there was no collinearity between the two variables. Table IV shows the calculated inactivation rate constants with the Equation 1 and the percent error between the calculated and measured constants shown in Table III.

TABLE IV

CAlculated InACTIVATION RATE CONSTANTS Using EQUATION 2 AND ERROR FROM MEASURED CONSTANTS

\begin{tabular}{|c|c|c|c|}
\hline Date & Container Type & $\begin{array}{c}\text { Calculated } k \\
\left(\text { hour }^{-1}\right)\end{array}$ & $\begin{array}{c}\text { Error between } \\
\text { calculated and } \\
\text { measured } k \\
(\%)\end{array}$ \\
\hline 9 Oct 2010 & 100-mL Bottles & 1.3 & -20 \\
\hline 16 Oct 2010 & P-B-U & 0.59 & 4.0 \\
\hline 8 April 2011 & 2-L Bottle & 0.51 & 31 \\
\hline 6 May 2011 & P-B-C & 2.1 & 6.6 \\
\hline 6 May 2011 & P-W-C & 1.7 & -0.90 \\
\hline 6 May 2011 & 2-L Bottle & 1.3 & 45 \\
\hline 19 Aug 2011 & P-B-U & 1.7 & -18 \\
\hline 19 Aug 2011 & P-B-C & 2.7 & 12 \\
\hline 19 Aug 2011 & P-W-C & 2.2 & -12 \\
\hline
\end{tabular}

Abbreviations: P: Pan, B: Black, W: White, U: Uncovered, C: Covered

\section{Design of Solar Exposure Tank}

Results from the experiments of water depths of 2.2 and $13.3 \mathrm{~cm}$ revealed no difference in the inactivation rate constants of total coliforms in the two containers. Therefore, the community water treatment system can be designed so that the water in the sun exposure tank is up to 13.3 $\mathrm{cm}$ deep. By designing the height of the UV tank to be one concrete masonry unit (CMU) block tall (about $20 \mathrm{~cm}$ ), the design depth of water can be effectively treated within this tank capacity. Tests were not conducted to determine the maximum allowable effective depth of the UV tank, but it is expected that there is a greater range of effectiveness than defined in this study. Tests were conducted simply to arrive at a reasonable design parameter for the recommended sun exposure tank size.

In the control experiment conducted without sun exposure, total coliform concentrations decreased from the initial $5475 \mathrm{MPN} / 100 \mathrm{~mL}$ to approximately $2000 \mathrm{MPN} / 100 \mathrm{~mL}$ in 6 hours. Therefore, only limited disinfection occurred without sunlight exposure. 


\section{DISCUSSION}

\section{Use of Contour Plots}

The contour plot of Figure 4 can be used by developers of the system who have science and engineering knowledge. These developers can later teach system operators, who may have limited literacy, a simplified operation, as described later in this Discussion. The plots can be used by the developers as follows. If the water temperature inside the covered container were $35^{\circ} \mathrm{C}$ and the UV index for that day were 10 , the inactivation rate constant, $k$, from the contour plot would be approximately $1.4 \mathrm{~h}^{-1}$. With the inactivation rate constant determined from the plot, Equation 1, rearranged and solved for time, can be used to estimate the number of hours needed for disinfection.

$$
t=\frac{\ln \frac{C_{f}}{C_{o}}}{-k}
$$

(EQ 1 REARRANGED)

The initial concentration of coliform bacteria must be known to use this equation, or else a reasonable estimate must be obtained during initial field tests. For example, using the maximum filtered concentration of total coliforms in this study $(4,106 \mathrm{MPN} / 100 \mathrm{~mL}$, see Table II), a final acceptable concentration of $1 \mathrm{MPN} / 100 \mathrm{~mL}$, and the inactivation constant from the previous paragraph of $1.4 \mathrm{~h}^{-1}$, then Equation 1 (rearranged) yields a necessary exposure time of 5.9 hours, which could be rounded up to ensure adequately treated water for the users. The process will take less time on days with high temperature and UV light. On cloudy days with lower UV light and lower temperature, the water should be exposed for a longer time, assuming enough daylight hours, to inactivate the bacteria properly.

To make this procedure more accessible to treatment system operators, Figure 5 has been generated. This figure uses the same data as Figure 4, but with time (in hours) as the contour lines. The plot assumes a daily filtered coliform concentration of 4,106 MPN/100mL and a final concentration of $1 \mathrm{MPN} / 100 \mathrm{~mL}$. Rearranged Equation 1 is then used to calculate the exposure time (in hours) based on each of the nine inactivation rate constants (Table III) used to generate Figure 4. Further, because UV index values may be difficult to access, pictures of typical weather conditions for various UV indices have been placed on the plot for user-friendliness. In this case, an operator can use Figure 5 to estimate the number of hours necessary to expose water to sunlight. In the case of a sunny day with an average water temperature in the covered tank of, for example, $35^{\circ} \mathrm{C}$, an operator can use the full sun figure (between UV indices of 10 and 12) on the vertical axis of Figure 5 and $35^{\circ} \mathrm{C}$ for water temperature on the horizontal axis. Drawing a horizontal line from the full sun figure and a vertical line from the $35^{\circ} \mathrm{C}$ temperature, the operator will find an intersection near the contour line of 6 hours, indicating that this would be the required sunlight exposure time. Figure 5 is also useful to show when it is not appropriate to conduct water treatment using this technique. On an overcast, relatively cold day, required exposure times could be as high as 14 hours, often longer than the number of sunlight hours in one day. 


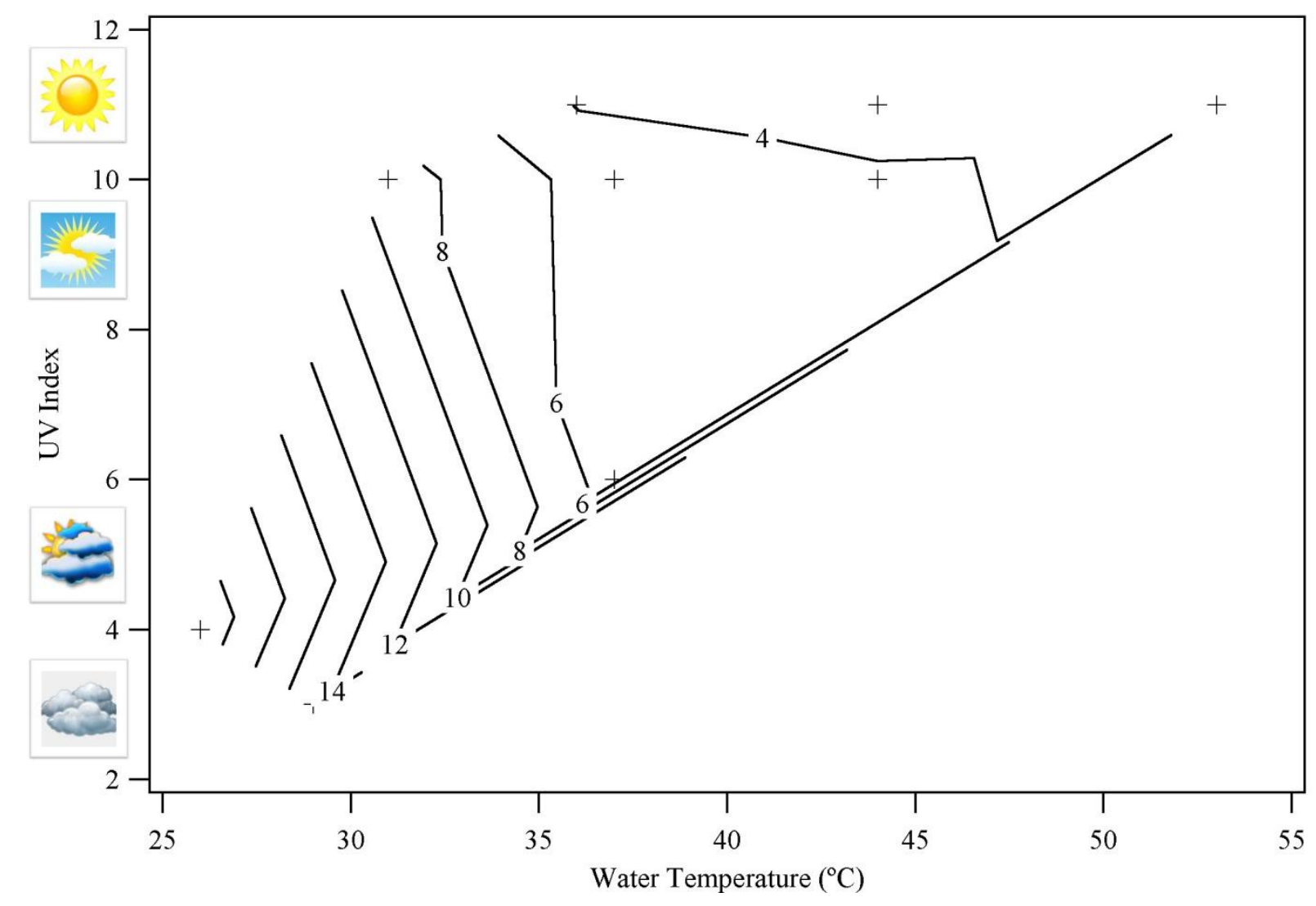

FIGURE 5

CONTOUR PLOT OF TIMES (IN HOURS) REQUIRED FOR SUNLIGHT INACTIVATION. THE TIME CAN BE FOUND FROM THE INTERSECTION OF THE VERTICAL LINE FROM THE WATER TEMPERATURE AXIS AND THE HORIZONTAL LINE FROM THE UV INDEX/WEATHER AXIS.

\section{Design and Operation and Maintenance of the Sun Exposure Tank}

Based on the results reported, a discussion follows on design and operation and maintenance items. A water depth of $13 \mathrm{~cm}$ is sufficient for disinfection, and the walls of the tank should be no more than $10 \mathrm{~cm}$ higher than the level of the water during sunlight exposure to minimize side shadows and to provide space for entrapment of heat under the plastic covering. Using a water-

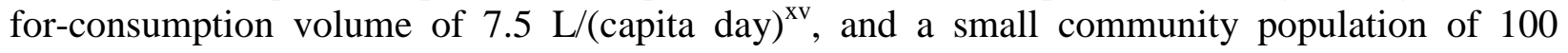
persons, then the required volume of water to be treated daily would be $750 \mathrm{~L}$. With a water depth of $13 \mathrm{~cm}$ in the sun exposure tank, the area of this tank would need to be $5.8 \mathrm{~m}^{2}$ in interior measurements. It is noted that wall heights are recommended to not exceed $10 \mathrm{~cm}$ above the water level. The tank size is not recommended to be larger than needed because of the structural supports needed for such a tank. Additional consideration must be given to locating the sun exposure tank relative to the path of the sun so that no shadows are cast during the duration of disinfection. 
Operationally, measures must be taken to keep the tanks clean and the filtration sand free of external contaminants. Bottles used to hold the disinfected water should be disinfected themselves, likely with a low concentration bleach solution.

Developers of this system should be knowledgeable of science and engineering fundamental concepts. However, they must make the system useful for a potential operator who may have limited knowledge and literacy. Developers should provide a custom chart to direct the operators to the proper number of hours of sun exposure for the water, given the temperature, time of year and cloud cover. Air temperature can be measured with a simple thermometer. The cloud cover can be divided into portions, such as sunny, partly cloudy, and mostly cloudy, which would also account for UV index, as shown in Figure 5.

Well-trained operators of the system would be valuable resources in the community and could operate the treatment systems as a micro-business by selling the treated water in disinfected bottles at an affordable rate that could sustain the labor and material costs of running the system. Further, education and pollution prevention activities, such as protection of drinking water sources, to improve human health and the environment would be necessary for the overall functioning of the treatment system. Applications of this humanitarian engineering concept to community-specific conditions would also be dependent on proper operation and maintenance activities.

\section{CONCLUSIONS}

Based on the results from all solar exposure experiments, the most effective design for an electricity-free, community-scale water treatment system would be a black sun exposure tank at most $20 \mathrm{~cm}$ high and with up to $13.3 \mathrm{~cm}$ of water depth, covered with a Husky® 2-MIL plastic drop cloth or equivalent. This configuration utilizes the optical and thermal properties of the sun, thus increasing the rate of disinfection. The time for sun exposure can be determined based on experiments of UV index (or weather conditions or solar irradiance measurements if possible) and water temperature. Figure 4 and 5 demonstrate how such a sun exposure time can be determined.

The effectiveness of the covered black tank is attributed to the increase in water temperature resulting from the plastic cover and to the darker color absorbing UV light and transforming the light into heat ${ }^{\mathrm{xvi}}$. In countries where this particular brand is not available, these experiments can easily be repeated with available clear plastics. To do so, samples of clear plastics can be tested with a spectrophotometer in a laboratory at the location of the community or in the location of the aid organization during the planning process of the water treatment system.

Further work for this research includes further experiments with a consistent tank covering and operation and maintenance metrics, such as evaluating how the plastic covering may degrade with sunlight over time and how the sun exposure tank should be cleaned.

\section{ACKNOWLEDGMENTS}

The authors would like to thank the University of Mississippi Sally McDonnell Barksdale Honors College for financial support for this research and the numerous students who assisted in conducting experiments, most notably Danielle Usner. The authors also thank three anonymous reviewers who provided comments that led to the improvement of this paper. 


\section{REFERENCES}

${ }^{i}$ World Health Organization (WHO) and United Nations Children's Fund (UNICEF), Progress on Drinking Water and Sanitation - 2012 Update (New York: UNICEF/WHO, 2012), 2.

ii "Managing Water in the Home: Accelerated Health Gains from Improved Water Supply," World Health Organization (WHO), Accessed April 7, 2013, http://www.who.int/water_sanitation_health/dwq/wsh0207/en/index4.html.

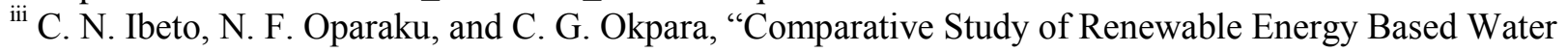
Disinfection Methods for Developing Countries," Journal of Environmental Science \& Technology 3, no. 4 (2010), 226-31.

${ }^{\text {iv }}$ K. McGuigan, R. Conroy, H. J. Mosier, M. du Preez, E. Ubonba-Jaswa, P. Fernandez Ibañez, "Solar water disinfection (SODIS): A review from bench-top to roof-top," Journal of Hazardous Materials, no. 235-236 (2012), 29-46.

${ }^{v}$ B. Sommer, A. Mariño, Y. Solarte, M. L. Salas, C. Dierolf, C. Valiente, D. Mora, R. Rechsteiner, P. Setter, W. Wirojanagud, H. Ajarmeh, A. Al-Hassan, M. and Wegelin, "SODIS - An Emerging Water Treatment Process," Journal of Water Supply: Research and Technology -- Aqua 46, no. 3 (1997), 12737.

${ }^{v i}$ K. G. McGuigan, T. M. Joyce, R. M. Conroy, J. B. Gillespie, and M. Elmore-Meegan, "Solar Disinfection of Drinking Water Contained in Transparent Plastic Bottles: Characterizing the Bacterial Inactivation Process," Journal of Applied Microbiology 84, no. 6 (1998), 1138-48.

${ }^{\text {vii }}$ M. Berney, Weilenmann, H. U. Simonetti, and T. Egli, 2006 "Efficacy of Solar Disinfection of Escherichia coli, Shigella flexneri, Salmonella Typhimurium and Vibrio cholerae," Journal of Applied Microbiology 101, no. 4 (2006), 828-36.

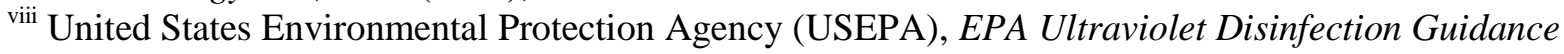
Manual (Washington, DC: 2003), Report EPA 815-D-03-007.

${ }^{\text {ix } U S E P A, ~ E P A ~ U l t r a v i o l e t ~ D i s i n f e c t i o n ~ G u i d a n c e ~ M a n u a l . ~}$

${ }^{x}$ S. Mtapuri-Zinyowera, N. Midzi, C. E. Muchaneta-Kubara, T. Simbini, and T. Mduluza, "Impact of Solar Radiation in Disinfecting Drinking Water Contaminated with Giardia Duodenalis and Entamoeba Histolytica/dispar at a Point-of-use Water Treatment," Journal of Applied Microbiology 106, no. 3 (2009), 847-52.

xi "How UV Index is Calculated," United States Environmental Protection Agency (USEPA), Accessed May 30, 2013, http://www2.epa.gov/sunwise/calculating-uv-index.

${ }^{x i i}$ R. A. Ryntz, Plastics and Coatings: Durability-Stabilization Testing (Munich, Germany: Hanser Gardner Publications, 2001).

xiii American Public Health Association/American Water Works Association/Water Environment Federation, Standard Methods for the Examination of Water and Wastewater, $21^{\text {st }}$ edition (2005).

${ }^{\text {xiv }}$ USEPA, EPA Ultraviolet Disinfection Guidance Manual.

${ }^{x v}$ G. Howard and J. Bartram, "Domestic water quantity, service level and health," (New York, NY: World Health Organization 2003), 9.

${ }^{x v i}$ World Health Organization (WHO), International Agency for Research on Cancer, 1997 Solar and Ultraviolet Radiation, Report IARC Monographs on the Evaluation of Carcinogenic Risks to Humans 55 (1997). 